\title{
Levels and distribution of organochlorine pesticides and hexachlorobutadiene in soils and terrestrial organisms from a former pesticide-producing area in Southwest China
}

\author{
Zhenwu Tang ${ }^{1} \cdot$ Qifei Huang $^{2} \cdot{\text { Zhiqiang } \mathrm{Nie}^{2} \cdot \text { Yufei Yang }}^{2} \cdot$ Jun Yang $^{3} \cdot$ \\ Dan $\mathrm{Qu}^{1} \cdot$ Jiali Cheng ${ }^{4}$
}

Published online: 22 August 2015

(C) Springer-Verlag Berlin Heidelberg 2015

\begin{abstract}
The contamination of organochlorine pesticides (OCPs) and hexachlorobutadiene (HCBD) in soils, plants, and terrestrial fauna from a former pesticide-producing area in Southwest China was investigated. High levels of OCP residues ( $\Sigma$ HCHs and $\Sigma$ DDTs of $3.89-13,386$ and $23.3-11,186 \mathrm{ng} \mathrm{g}^{-1} \mathrm{dw}$, respectively) were found in the soils within the producing factory, indicating that the former pesticide factory brownfield site poses a high environment risk and that effective soil remediation is needed. The OCP concentrations in soils surrounding the pesticide factory were 1-2 orders of magnitude higher than in the other agricultural areas from China. Grass, vegetables, and tree leaves from the surrounding areas of the point source showed moderate OCP pollution, which was likely to be causing potential negative impacts on terrestrial ecosystem. OCP levels in terrestrial species from the studied area including insects, free-range chickens and birds were moderate, and were generally within accepted safe levels.
\end{abstract}

\section{Qifei Huang \\ huangqf@craes.org.cn \\ $\triangle$ Jiali Cheng \\ jlcheng77@163.com}

1 MOE Key Laboratory of Regional Energy and Environmental Systems Optimization, Environmental Research Academy, North China Electric Power University, Beijing 102206, China

2 State Key Laboratory of Environmental Criteria and Risk Assessment, Chinese Research Academy of Environmental Sciences, Beijing 100012, China

3 Center for Environmental Remediation, Institute of Geographic Sciences and Natural Resources Research, Chinese Academy of Sciences, Beijing 100101, China

4 National Institute for Nutrition and Health, Chinese Center for Disease Control and Prevention, Beijing 100021, China
$\beta-\mathrm{HCH}$ was the most prevalent isomer, implying that hexachlorocyclohexane $(\mathrm{HCH})$ residues were mainly derived from the degradation of technical $\mathrm{HCH}$. The dichlorodiphenyltrichloroethane (DDT) profiles reflected obvious degradation of technical DDT. In the study area, the concentrations of HCBD were $<0.02-5.59$, $0.03-24.6 \mathrm{ng} \mathrm{g}^{-1} \mathrm{dw}$ and $1.65-3.80 \mathrm{ng} \mathrm{g}^{-1} \mathrm{lw}$ in soils, plants, and animals, respectively, which were relatively low and not sufficient to cause observable adverse biological effects.

Keywords Organochlorine pesticides .

Hexachlorobutadiene - Bioaccumulation · Pesticide factory $\cdot$ Risks

\section{Introduction}

Organochlorine pesticides (OCPs) such as hexachlorocyclohexanes (HCHs) and dichlorodiphenyltrichloroethanes (DDTs) have been of increasing concern worldwide because of their persistence, potential for bioaccumulation, and toxicity toward nontarget organisms (Willett et al. 1998; Guo et al. 2014). Although the production and agricultural use of HCHs and DDTs have been banned in many countries, widespread pollution by these OCPs is still occurring in various environmental media and organisms from some countries including China, India and Columbia (Dhananjayan et al. 2011; Liu et al. 2013; Rojas-Squella et al. 2013; Tang et al. 2013; Guo et al. 2014; Pan et al. 2014), and high levels of OCPs in humans and animals have been reported in developing countries in recent years (Qu et al. 2010; Rojas-Squella et al. 2013). Therefore, there is an increasing need to better understand the sources of these chemicals and assess their potential ecological risks. 
From 1952 to 1983, China's total production of HCHs and DDTs was around 4 and 0.27 million tones, respectively (Li et al. 2001; Zhang et al. 2009a, b). In addition, lindane (primarily composed of $\gamma-\mathrm{HCH}$ ) and dicofol (contains DDTs) were widely produced in China in the past few years (Qiu et al. 2005; Tao et al. 2005). Extensive and long-term OCP production has resulted in contamination at many industrial sites in China. Previous studies have reported that concentrations of $\mathrm{HCHs}$ and DDTs were extraordinarily high in the topsoil from pesticide-producing factories, with a high potential for detrimental biological effects on organisms (Shi et al. 2009; Zhang et al. 2009a, b; Yu et al. 2011; Zhao et al. 2013). However, information regarding soil pollution around pesticide factories is still limited.

Owing to their high lipophilicity and strong resistance to degradation, OCPs are readily accumulated in biological organisms (Pan et al. 2014). Additionally, high concentrations of OCP residues in soils can be volatilized and subsequently enter into vegetation or animals through the air. Moreover, multiclass plants can easily absorb and accumulate OCPs from soils directly, and terrestrial animals may bioaccumulate OCPs through food chains (Dhananjayan et al. 2011; Zhang et al. 2011). As a result, vegetation and terrestrial animals around pesticide factories may be at risks. However, the adverse environmental effects of pesticides in soils are influenced by many factors, such as the OCP levels and interspecific differences in bioaccumulation (Dauwe et al. 2009; Zhao et al. 2013). Investigations of the levels of OCPs existing in terrestrial plants and animals within and surrounding pesticide factories can provide critical information for assessing human and animal health risks.

In this study, a former pesticide-producing factory in Southwest China was selected as a typical OCP-contaminated site and the levels of HCHs and DDTs in soil samples within and around the pesticide factory were measured. In addition, OCPs in terrestrial flora and fauna around the pesticide factory were analyzed to investigate the contamination levels as well as to estimate the effects of point source pollution by OCPs and its potential environmental risks.

Hexachlorobutadiene (HCBD), a chlorinated aliphatic hydrocarbon, has been listed as a candidate persistent organic pollutant by the Stockholm Convention owing to its toxicity, persistence, and potential for bioaccumulation (Tang et al. 2014; Zhang et al. 2014). This molecule is usually generated as a by-product during the production of chlorinated solvents (POPRC 2013). In the study pesticideproducing factory, various chlorinated solvents were produced and used extensively to manufacture other pesticides; HCBD is likely to has been generated unintentionally and released into the environment.
Therefore, the accumulation of HCBD in soils and terrestrial organisms was also investigated around the pesticide factory.

\section{Materials and methods}

\subsection{Study area}

The pesticide plant is located in the suburban area of Chongqing in Southwest China and has an enclosed area of $164,000 \mathrm{~m}^{2}$. From 1956 to 1983 , approximately 220,000 tones of technical $\mathrm{HCHs}$ were produced in the factory, while the production of DDTs was estimated to be more than 52,000 tones between 1956 and 1985. Before it was closed in 2008, more than 30 pesticides and intermediate chemicals including organochlorine, organophosphorus and pyrethroids were produced at this facility. The site has been contaminating the surrounding area for decades, and there are currently tens of thousands of people living around the abandoned factory.

\subsection{Sample collection}

In September 2011, soil samples were collected from sites within and surrounding the former pesticide plant. Within the factory, a total of 12 composite soil samples were collected from 0 to $20 \mathrm{~cm}$ below the concrete floors in former pesticide production workshops, warehouses, and offices. Meanwhile, 14 composite surface soil samples (0-20 cm deep) were taken from residential sites, farmlands, and unused lands $<1.0 \mathrm{~km}$ from the manufacturing facility, using a stainless steel shovel. Composite samples were prepared, consisting of five subsamples from every $100 \mathrm{~m}^{2}$ of land. Sampling locations are shown in Fig. 1. Soil samples were placed in a pre-cleaned aluminium box and freeze dried before being ground, homogenized, and stored at $-20{ }^{\circ} \mathrm{C}$ until analysis.

At the same time, zoysia (Zoysia sinica Hance, $n=6$ ), wolfsbane (Aconitum carmichaeli Debx, $n=4$ ), leaves of other plants including batata (Ipomoea batatas, $n=3$ ), paper mulberry (Broussonetia papyrifera, $n=3$ ), carrot (Daucus carota, $n=3$ ), soybean (Glycine max, $n=4$ ) and pumpkin (Cucurbita moschata, $n=3$ ) were collected from the eastern farmland adjacent to the factory $(<500 \mathrm{~m})$ using a small stainless shovel. The plant samples were washed with tap water, cut into lengths of $<1 \mathrm{~cm}$ and mixed well, after which they were freeze dried, ground, homogenized, and stored at $-20{ }^{\circ} \mathrm{C}$.

Within a week after the soil sampling, samples of terrestrial fauna, namely, ants (Polyrhachis vicina Roger), crickets (Gryllus testaceus Walker), grasshoppers (Acrida chinensis), locusts (Oxya chinensis), free-range chickens 
Fig. 1 Map of the sampling sites from the former pesticide producing area, Southwest China

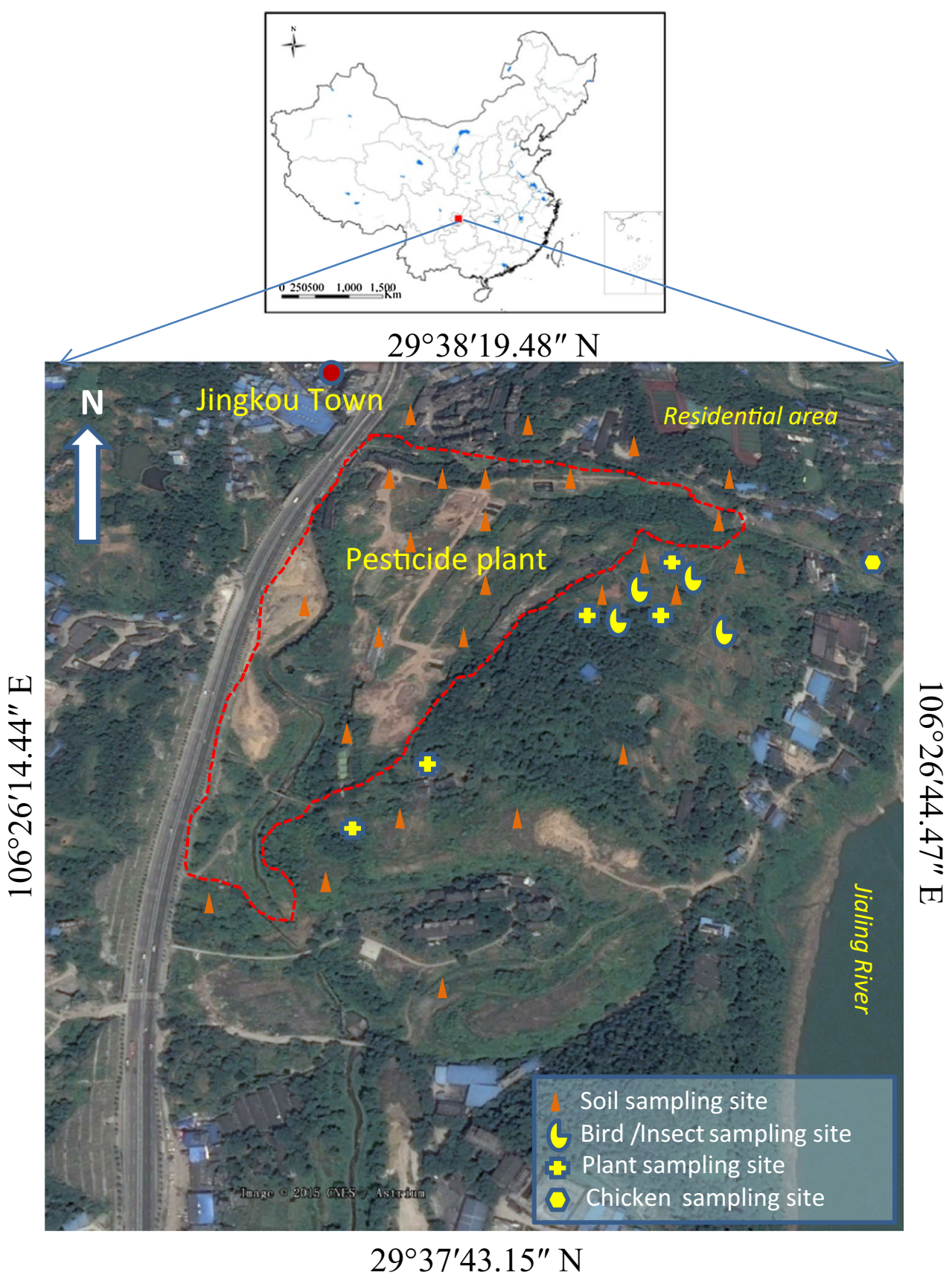

(Gallus gallusdomesticus), oriental turtle dove (Streptopelia orientalis), great tits (Parus major), and red-billed blue magpies (Urocissa erythrorhyncha) were collected. Overall, several hundred ants, locusts, grasshoppers, and crickets were collected separately using funnel traps (20 cm diameter). Oriental turtle dove $(n=3)$, great tits $(n=3)$, and blue magpies $(n=4)$ were collected from the eastern farmland using a clapnet. Additionally, a total of five chickens were collected from the villages $(<1 \mathrm{~km})$ surrounding the pesticide plant. Complete organisms of the smaller biological samples were obtained. Only the muscle tissues of chickens and other wild birds were collected. The animal samples were frozen, then thawed and rinsed individually with deionized water to remove impurities. Then all biological samples were freeze dried, ground to a powder, and stored at $-20{ }^{\circ} \mathrm{C}$ until analysis.

\subsection{Sample preparation}

The soil, plant and terrestrial animal samples were analyzed for pesticides and HCBD using the method described by Tang et al. (2014). Briefly, $10 \mathrm{~g}$ of freeze-dried soils or 
plant materials was mixed with $30 \mathrm{~mL}$ of hexane/dichloromethane $(1: 1, \mathrm{v} / \mathrm{v})$, then sonicated in an ultrasonic bath for $30 \mathrm{~min}$. The solvent was collected and the procedure was repeated, after which the two extracts were combined and activated copper was added to remove the elemental sulfur. Next, the extracts were concentrated for subsequent cleaning, transferred to a $12-\mathrm{mm}$ i.d. glass column containing $5 \mathrm{~cm}$ of alumina and $5 \mathrm{~cm}$ of silica gel, and eluted with $70 \mathrm{~mL}$ hexane/dichloromethane $(7: 3, \mathrm{v} / \mathrm{v})$. The eluates were concentrated under a nitrogen stream and diluted to a final volume of $0.5 \mathrm{~mL}$ with hexane. Internal standards were added into the extract prior to the analysis by gas chromatography (GC).

The procedure for extraction of the chemicals from the animal samples was the same as that described above, but $5-10 \mathrm{~g}$ of each freeze-dried sample was extracted. One aliquot of the extract was used for gravimetric determination of the lipid content, while another was used for chemical analysis after purification on a column containing $5 \mathrm{~cm}$ of neutral alumina and $8 \mathrm{~cm}$ of neutral silica gel.

\subsection{Sample analysis}

Organochlorine pesticides and HCBD were identified using an Agilent 7890 gas chromatograph equipped with a $\mathrm{Ni}^{63}$ electron capture detector and an Agilent HP-5 column (30 $\mathrm{m} \times 0.32 \mathrm{~mm}$ i.d., film thickness: $0.25 \mu \mathrm{m})$. Nitrogen (99.99\% purity) was applied as the carrier gas at $1.0 \mathrm{~mL} \mathrm{~min}^{-1}$. The injector and detector temperatures were maintained at 250 and $315{ }^{\circ} \mathrm{C}$, respectively. The column temperature was programmed as follows: initial temperature of $60{ }^{\circ} \mathrm{C}$ for $2 \mathrm{~min}$, followed by an increase to $160{ }^{\circ} \mathrm{C}$ at $20{ }^{\circ} \mathrm{C} \min ^{-1}$, then to $210{ }^{\circ} \mathrm{C}$ at $5{ }^{\circ} \mathrm{C} \min ^{-1}$ and finally to $270{ }^{\circ} \mathrm{C}$ at $5{ }^{\circ} \mathrm{C} \mathrm{min}^{-1}$, where it was held for $3 \mathrm{~min}$. For analysis, $1-\mu \mathrm{L}$ aliquots of samples were injected in splitless mode.

Total organic carbon (TOC) in soil was measured on a Liqui TOC (Elementar, Germany) at a combustion temperature of $950{ }^{\circ} \mathrm{C}$.

\subsection{Quality assurance/quality control}

All standard solutions were purchased from Supelco (USA). The identities of the target compounds were determined based on comparison with the average retention times of individual authentic standards and confirmed using an Agilent gas chromatograph/mass spectrometer (Agilent 7890 GC/5975 MSD; Agilent Technologies). The average retention times of $\mathrm{HCBD}, \alpha-\mathrm{HCH}, \beta-\mathrm{HCH}, \gamma-$ $\mathrm{HCH}, \delta$-HCH, $o, p^{\prime}$-DDE, $p, p^{\prime}$-DDE, $o, p^{\prime}$-DDD, $p, p^{\prime}$ DDD, $o, p^{\prime}$-DDT and $p, p^{\prime}$-DDT were at $8.043,13.597$, $14.357,14.551,15.259,20.163,21.222,21.512,22.635$, 22.751 and $23.900 \mathrm{~min}$, respectively. 2,4,5,6-tetrachloro- $m$-xylene was used as a surrogate standard and pentachloronitrobenzene was used as an internal standard. Procedural blanks and samples spiked with standard mixture were used to monitor the method performance and matrix effects.

The mean spiked HCBD recoveries were 91.6, 78.2, and $82.0 \%$ in the soil, plant, and animal samples, respectively. The mean recoveries of OCP in the soil and organism samples were $74.9-119.4 \%$. The surrogate standard recoveries in all samples ranged from 76.2 to $81.7 \%$. The method detection limits (MDLs) were defined as three times the baseline noise. The MDLs for HCBD and the OCPs were 0.02 and $0.01-0.07 \mathrm{ng} \mathrm{g}^{-1}$ dry weight, respectively, in each of the matrices. Reported concentrations were not corrected for surrogate recovery in this study.

\section{Results and discussion}

\subsection{OCP residues in soils}

The arithmetic means, medians and ranges of the $\mathrm{HCH}$ ( $\Sigma$ HCHs, sum of isomers $\alpha-+\beta-+\gamma-+\delta$ - $\left.\alpha_{-}{ }_{-}\right)$and DDT $(\Sigma$ DDTs $=$ DDT + DDE + DDD $)$ concentrations in the soil samples within and surrounding the pesticideproducing factory are summarized in Table 1 . Within the former factory, the concentrations of $\Sigma \mathrm{HCHs}$ and $\Sigma$ DDTs ranged from 3.89 to $13,386 \mathrm{ng} \mathrm{g}^{-1}$ dry weight (dw) and $5.42-11,186 \mathrm{ng} \mathrm{g}^{-1} \mathrm{dw}$, respectively. The levels of $\mathrm{HCH}$ isomers and DDT-related compounds are also presented in Table 1.

Within the former factory, the average concentrations of $\Sigma$ HCHs and 5 DDTs were 1854 and $2482 \mathrm{ng} \mathrm{g}^{-1}$ of soils, respectively. In the soil samples, the concentrations of $\Sigma \mathrm{HCHs}$ and $\Sigma$ DDTs varied separately by a factor of about 3000 and 500, indicating uneven distributions of OCPs as a result of the production plants being distributed irregularly at the site. The highest levels of $\Sigma$ HCHs and $\Sigma$ DDTs were found in warehouse site, which might be related with past store of pesticide products. In addition, some higher levels of HCHs and DDTs were investigated in the open area of waste equipments, likely reflecting the chemical releases from these waste facilities. HCHs and DDTs exhibited similar contamination levels in this study, which was consistent with their historical production at the site. Previous studies also reported soil pollution with $\mathrm{HCHs}$ and DDTs in other former pesticide-producing plants in China (Shi et al. 2009; Zhang et al. 2009a, b; Yu et al. 2011; Zhao et al. 2013). The OCP concentrations in soils from different areas are summarized in Table 2. Although the mean concentrations of OCPs in the soils in the study area were comparable to concentrations found in soils from 
Table 1 Concentrations of HCBD, HCHs and DDTs $\left(\mathrm{ng} \mathrm{g}^{-1} \mathrm{dw}\right)$ and total organic carbon (TOC, $\mathrm{g} \mathrm{kg}^{-1}$ ) in the soils within and surrounding the former pesticide producing factory

\begin{tabular}{|c|c|c|c|c|c|c|}
\hline & \multicolumn{3}{|c|}{ Within factory $(n=12)$} & \multicolumn{3}{|c|}{ Surrounding factory $(n=14)$} \\
\hline & Range & Mean & Median & Range & Mean & Median \\
\hline TOC & $3.32-13.5$ & 5.57 & 5.37 & $2.35-6.08$ & 4.07 & 3.61 \\
\hline HCBD & $<0.02-5.59$ & 1.45 & 0.52 & $<0.02-4.27$ & 0.48 & 0.07 \\
\hline$\alpha-\mathrm{HCH}$ & $0.51-2610$ & 446 & 12.4 & $11.9-1885$ & 253 & 38.2 \\
\hline$\beta-\mathrm{HCH}$ & $1.84-10,464$ & 1336 & 86.9 & $10.5-2854$ & 550 & 181 \\
\hline$\gamma-\mathrm{HCH}$ & $0.50-260$ & 39.9 & 4.59 & $0.15-289$ & 45.1 & 5.77 \\
\hline$\delta$-HCH & $1.04-232$ & 32.3 & 4.78 & $1.87-1153$ & 102 & 6.67 \\
\hline$o, p^{\prime}-\mathrm{DDE}$ & $0.34-41.7$ & 10.2 & 2.82 & $<\mathrm{MDL}-14.5$ & 2.19 & 0.29 \\
\hline$p, p^{\prime}$-DDE & $5.36-710$ & 184 & 136 & $4.35-459$ & 55.6 & 20.2 \\
\hline$o, p^{\prime}$-DDD & $0.17-1606$ & 149 & 13.4 & $<$ MDL-491 & 40.6 & 3.34 \\
\hline$p, p^{\prime}$-DDD & $2.63-2819$ & 283 & 29.6 & $<\mathrm{MDL}-64.9$ & 13.6 & 5.48 \\
\hline$o, p^{\prime}$-DDT & $0.18-1976$ & 339 & 20.4 & $0.17-99.1$ & 13.4 & 4.51 \\
\hline$p, p^{\prime}$-DDT & $3.88-8679$ & 1516 & 116 & $0.91-419$ & 87.0 & 31.8 \\
\hline$\Sigma \mathrm{HCHs}$ & $3.89-13,386$ & 1854 & 93.6 & $33.8-4926$ & 950 & 265 \\
\hline$\Sigma$ DDTs & $23.3-11,186$ & 2482 & 362 & $5.42-1050$ & 212.3 & 80.8 \\
\hline$\alpha-\mathrm{HCH} / \gamma-\mathrm{HCH}$ & $1.02-18.3$ & 7.47 & 4.83 & $1.04-87.5$ & 13.8 & 6.13 \\
\hline DDT/(DDD + DDE) & $0.04-17.8$ & 4.01 & 1.49 & $0.05-2.95$ & 1.15 & 0.91 \\
\hline $\mathrm{DDE} /(\mathrm{DDD}+\mathrm{DDE})$ & $0.14-0.98$ & 0.62 & 0.68 & $0.03-1.00$ & 0.67 & 0.68 \\
\hline
\end{tabular}

$D D T$ including $p, p^{\prime}$-DDT and $o, p^{\prime}$-DDT; $D D D$ including $p, p^{\prime}$-DDD and $o, p^{\prime}$-DDD; $D D E$ including $p, p^{\prime}$ $\mathrm{DDE}$ and $o, p^{\prime}$-DDE; $M D L$, the method detection limit contaminated sites in Beijing, Yangzhou, and Hangzhou, China (Shi et al. 2009; Zhang et al. 2009a, b; Yu et al. 2011), the maximum concentration of both $\Sigma \mathrm{HCH}$ and $\Sigma$ DDTs measured in the present study appeared to be lower. This may have been due to the relatively earlier stoppage of OCP production at this investigated site. However, OCP concentrations in the soils within the contaminated site were 1-3 orders of magnitude higher than those found in soils from other agricultural fields and urban areas, suggesting that this abandoned industrial site was heavily contaminated with HCHs and DDTs (Table 2).

The concentrations of $\Sigma \mathrm{HCH}$ and $\Sigma$ DDTs in the soils around the abandoned factory were lower than those observed in soils within the factory (Table 1). As expected, the levels of OCPs in the soils surrounding the pesticide factory were 1-2 orders of magnitude higher than those found in the agricultural soils from the Haihe Plain, Yangtze River Delta, and Pearl River Delta in China (Gao et al. 2008; Tao et al. 2008; Zhang et al. 2009a, b). The OCP levels were comparable to concentrations found in soils from paddy fields with high amounts of $\mathrm{HCH}$ and DDT residues in Northeast India (Mishra et al. 2012). The data reported here suggest that the surface soils surrounding the former pesticide factory have been subjected to relatively high levels of OCP pollution. Relatively levels of HCHs and DDTs were found in the sites located the south of factory, which maybe reflected the effects of the dominant wind direction. Another main impact factor of the investigated OCPs appeared to be soil organic carbon $(p<0.05)$, which had a positive influence on DDTs and HCHs. Nevertheless, the highest TOC-normalized concentrations were not observed at sites nearest to the production plant. Similar results have been reported for soils around a pesticide factory in Zibo, China (Zhao et al. 2013). Overall, these findings indicate that the migration and distribution of OCPs in soil is a complex process affected by many factors.

Four $\mathrm{HCH}$ isomers were detected in the soil within and around the abandoned pesticide factory. Within the former factory, the average composition of $\mathrm{HCH}$ isomers in the soil samples was $\alpha$-HCH: $21.4 \%, \beta$-HCH: $67.7 \%, \gamma$-HCH: $5.11 \%$, and $\delta$-HCH: $5.76 \%$. Technical-grade $\mathrm{HCH}$ is usually a mixture of $\alpha-\mathrm{HCH}(71 \%), \beta-\mathrm{HCH}(6 \%), \gamma-\mathrm{HCH}$ (14\%), and $\delta$-HCH (9 \%) in China (Lin 1996), with $\beta$ $\mathrm{HCH}$ being the isomer that is most stable and readily accumulated in soil (Walker et al. 1999). Moreover, the isomers of $\alpha-\mathrm{HCH}$ and $\gamma-\mathrm{HCH}$ can be transformed into $\beta$ $\mathrm{HCH}$ in the environment (Walker et al. 1999; Li et al. 2001). The high percentage of $\beta$-HCH implied that technical $\mathrm{HCH}$ production had been stopped for many years (Zhao et al. 2013). A similar composition of $\mathrm{HCH}$ isomers ( $\beta$-HCH representing $78.3 \%$ of the $\Sigma \mathrm{HCHs}$ ) was measured in the soils surrounding the factory. The ratio of $\alpha-\mathrm{HCH} / \gamma-$ $\mathrm{HCH}$ is often used as an indicator of recent $\gamma-\mathrm{HCH}$ input into the environment (Abhilash and Singh 2008). In the present study, most of the ratios of $\alpha$ to $\gamma-\mathrm{HCH}$ within the 


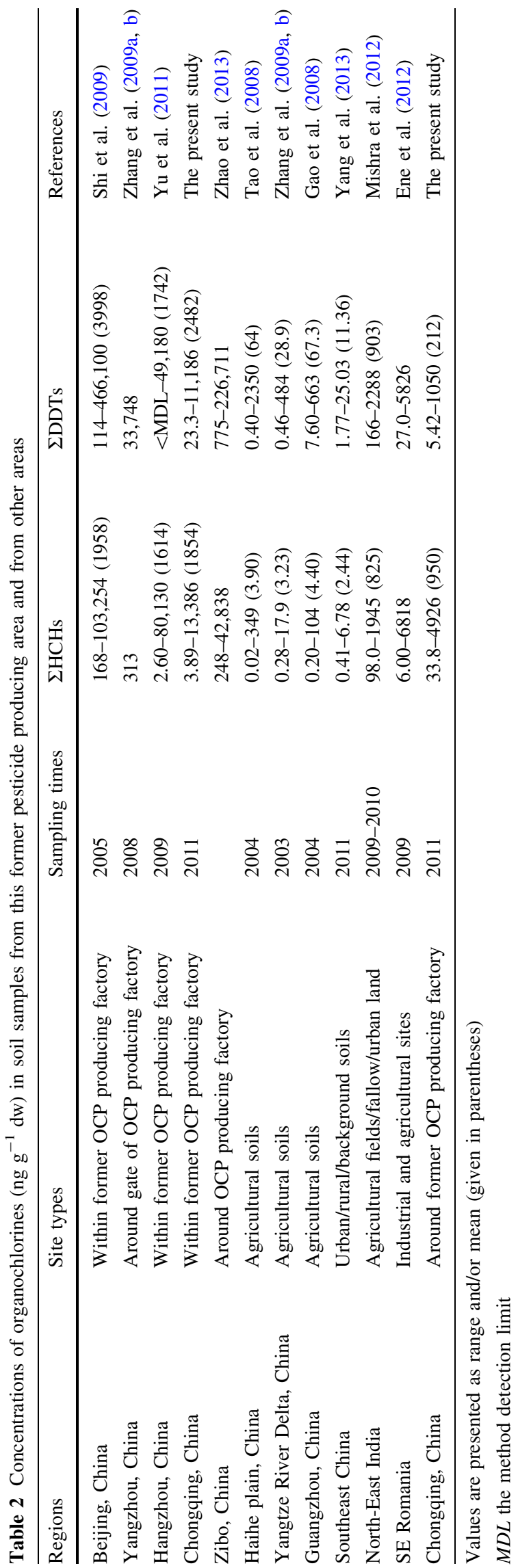

factory, ranged from 3 to 7 indicating that they were primarily derived from historical production of technical $\mathrm{HCH}$. Additionally, some of the ratios were found to be $>7$ in soils surrounding the factory. This finding is reasonable since $\gamma-\mathrm{HCH}$ is less stable than $\alpha-\mathrm{HCH}$ and can isomerize to $\alpha-\mathrm{HCH}$, which would cause the ratio to increase gradually after long-term contamination by technical $\mathrm{HCH}$ (Willett et al. 1998).

The composition of DDTs was similar within and around the pesticide factory. $p, p^{\prime}$-DDT dominated the DDT-related compounds, with a mean of 45.5 and $59.3 \%$ in the soil samples within and around the former factory, respectively. This was followed by $p, p^{\prime}$-DDE, which had corresponding abundances of 26.4 and $14.6 \%$. In most samples, the levels of $p, p^{\prime}$-DDT were much higher than those of $o, p^{\prime}$-DDT, which is consistent with the technical DDT composition. Generally, technical DDT contains $77.1 \% p, p^{\prime}$-DDT, $14.9 \% o, p^{\prime}$-DDT, $4 \% p, p^{\prime}$-DDE, and $<5 \%$ others (Bopp 1982; Zhu et al. 2005). The ratio of DDT/(DDD + DDE) with a reference value of 1.0 can be used to assess the application time of DDT (Tao et al. 2008). Samples with ratios of DDT/(DDD + DDE) $>1$ were found in most of the sites studied (Table 1), further demonstrating the historical contamination with technical DDT. DDT can be biodegraded to DDE under aerobic conditions and to DDD under anaerobic conditions (Aislabie et al. 1997). In this study, most values of the DDE/ (DDD + DDE) ratio exceeded 0.5, indicating that DDT degradation had happened largely under aerobic conditions in the soils.

\subsection{OCP pollution in plants}

The OCP contents in plants surrounding the abandoned pesticide factory are presented in Fig. 2. Residues of OCPs in plants ranged from 21.5 to $328 \mathrm{ng} \mathrm{g}^{-1} \mathrm{dw}$ for $\Sigma \mathrm{HCHs}$ and 26.5-484 $\mathrm{ng} \mathrm{g}^{-1} \mathrm{dw}$ for $\Sigma$ DDTs. Consistent with the results observed for the soil samples, the concentration of $\Sigma$ DDTs was comparable to that of $\Sigma \mathrm{HCHs}$ in plants. However, large interspecies differences were observed in the OCP concentrations of plants, and all chemicals were found at higher concentrations in wolfsbane than in other species, indicating different OCP accumulative capacities. There is currently little information available regarding OCP concentrations in plants around other former pesticide factories, however, contamination with OCPs has been reported in various plants, including vegetables, grass, and trees from farms and industrial regions (Wang et al. 2007; Lin et al. 2008; Pan et al. 2014). Inconsistencies in species, growth, and development of plants have made it difficult to draw comparisons, so simple comparisons were made using the levels of $\Sigma \mathrm{HCH}$ and $\Sigma$ DDTs when possible. The OCP concentrations found in plants from different regions 
Fig. 2 Levels of organochlorine pesticides and hexachlorobutadiene in plants (a) and terrestrial animals (b) from the former pesticide producing area, Southwest China. The bars indicate the standard deviations
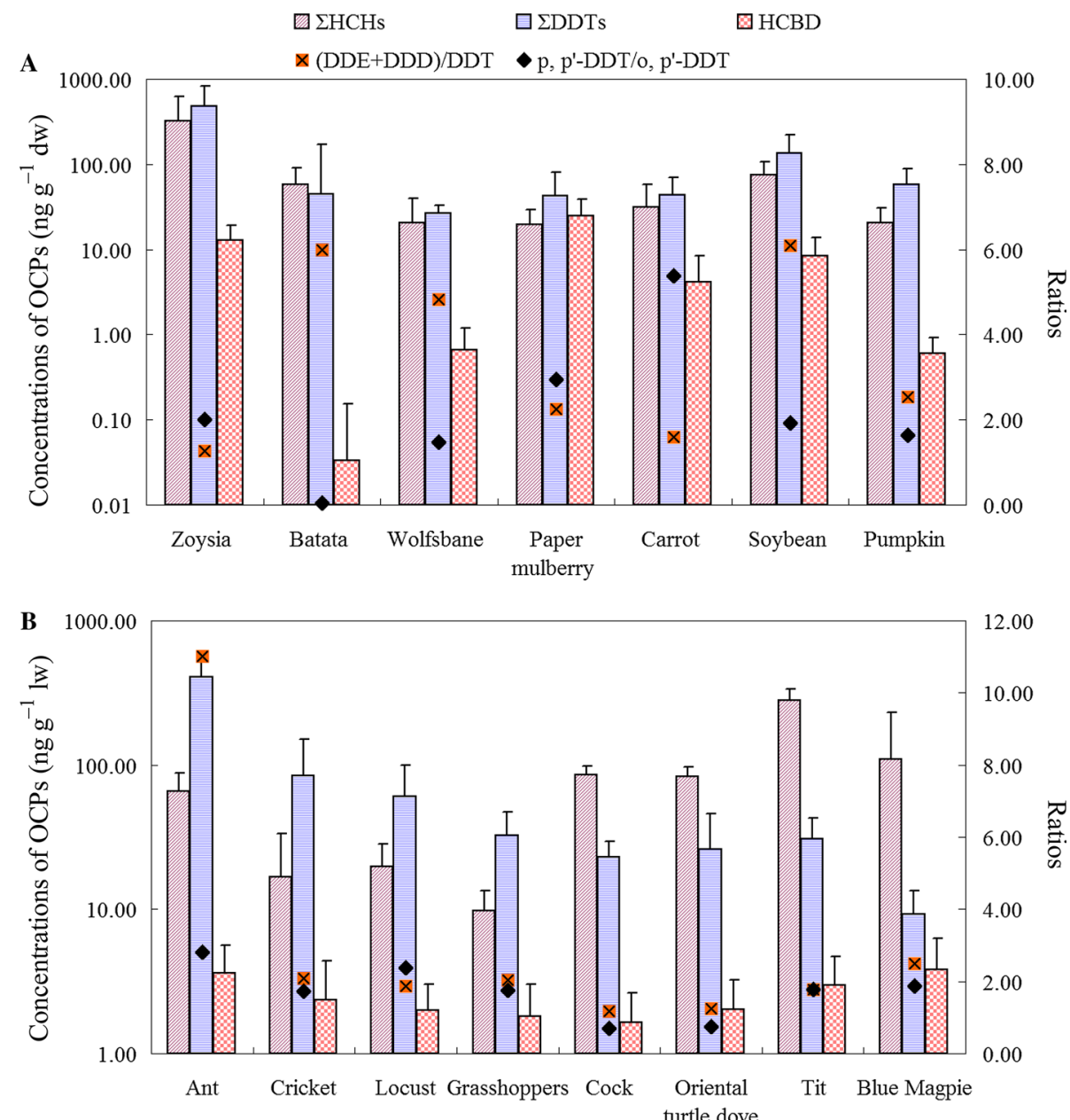

are shown in Table 3. In general, the concentrations of both HCHs and DDTs in plants were one order of magnitude higher in the present contaminated site than in other areas (Wang et al. 2007; Lin et al. 2008; Yi et al. 2012; Tarcau et al. 2013; Pan et al. 2014). These findings confirm that the contaminated sites are significant sources of pollution if left untreated, resulting in local and regional plant contamination.

As shown in Fig. 3a, the $\beta$-HCH ranged from 13.9 to $62.0 \%$ in the seven plant species, with a mean of $37.9 \%$. The accumulation of $\beta-\mathrm{HCH}$ in plant samples implies that $\mathrm{HCH}$ residues are primarily derived from the former pesticide factory. Notably, the ratio of $\alpha-\mathrm{HCH} / \gamma-\mathrm{HCH}$ in some plants was less than the ratio of 3-7 found in technical $\mathrm{HCH}$ (Fig. 3a). However, pure lindane was never produced in this former factory; therefore, the relatively lower ratios of $\alpha-\mathrm{HCH} / \gamma-\mathrm{HCH}$ might be related to differential accumulation or metabolism of $\mathrm{HCH}$ isomers in plants rather than fresh input of $\gamma-\mathrm{HCH}$. Larger interspecies differences in the ratios of $\alpha-\mathrm{HCH} / \gamma-\mathrm{HCH}$ were reported for agricultural crops from an intensive horticultural area in Hohhot, China (Wang et al. 2007).The profiles of DDT-related compounds in plants are presented in Fig. 4a. When compared with soil samples, an inversion between the dominance of DDT in favor of DDD was observed in the plant samples. $\mathrm{DDD}\left(p, p^{\prime}\right.$-DDD and $o, p^{\prime}$-DDT) was present at percentages higher than $47.7 \%$ of $\Sigma$ DDTs. The ratios of (DDD + DDE)/DDT ranged from 1.27 to 6.10, with a mean of 3.51 (Fig. 2a). The DDT metabolites were more prevalent than the parent materials, suggesting either efficient biotransformation of the parent materials in the plant systems or old sources of DDT contamination. In general, the $\mathrm{DDD} /(\mathrm{DDD}+\mathrm{DDE})$ ratios were $>0.5$, indicating that the biodegradation of DDT was anaerobic. As shown in Fig. 2a, the $p, p^{\prime}$-DDT/o, $p^{\prime}$-DDT ratio (mean $=2.19$ ) suggests that the DDTs in the plants were mainly derived from the technical DDT emissions from the former pesticide factory.

\subsection{Accumulation of OCPs in terrestrial fauna}

The HCHs and DDTs measured in various terrestrial animal samples are listed in Fig. 2b. The lipid normalized 


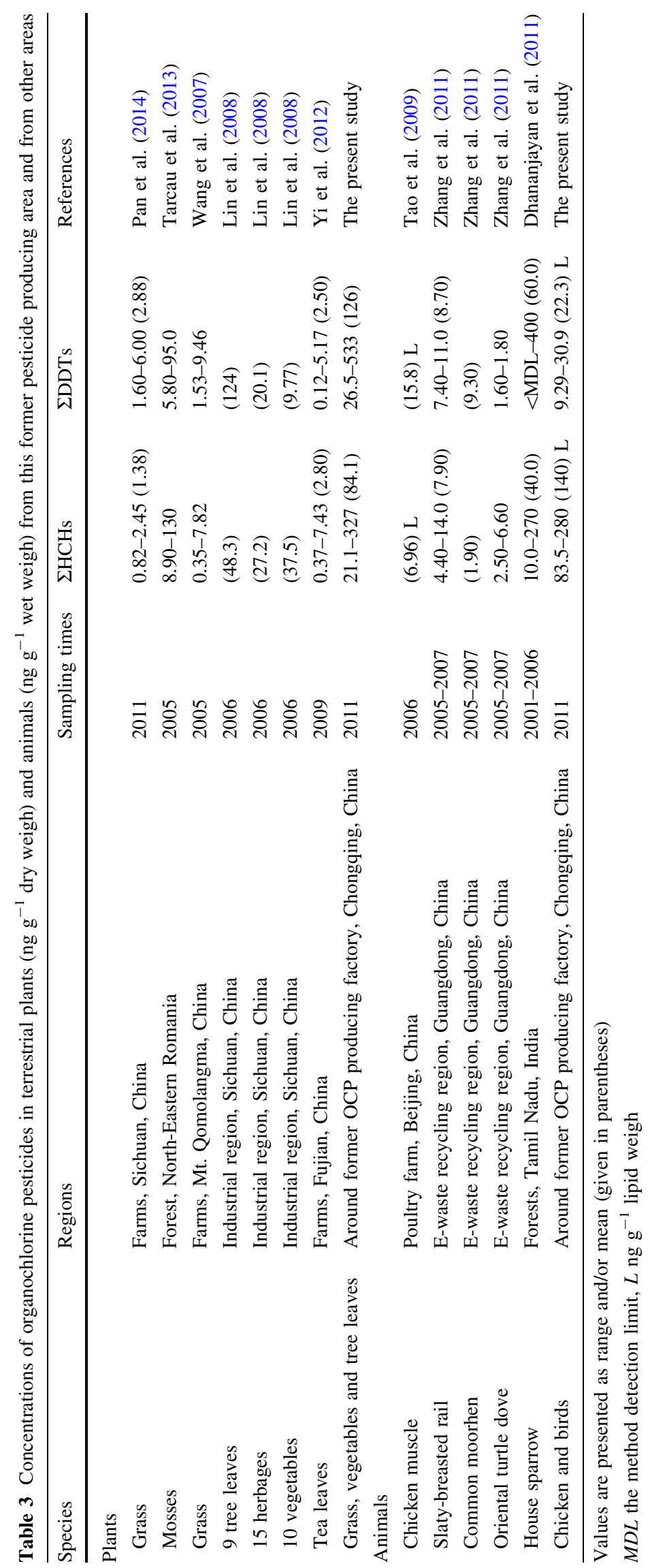


Fig. 3 The composition of $\mathrm{HCHs}$ in the plants (a) and terrestrial animals (b) from the former pesticide producing area, Southwest China
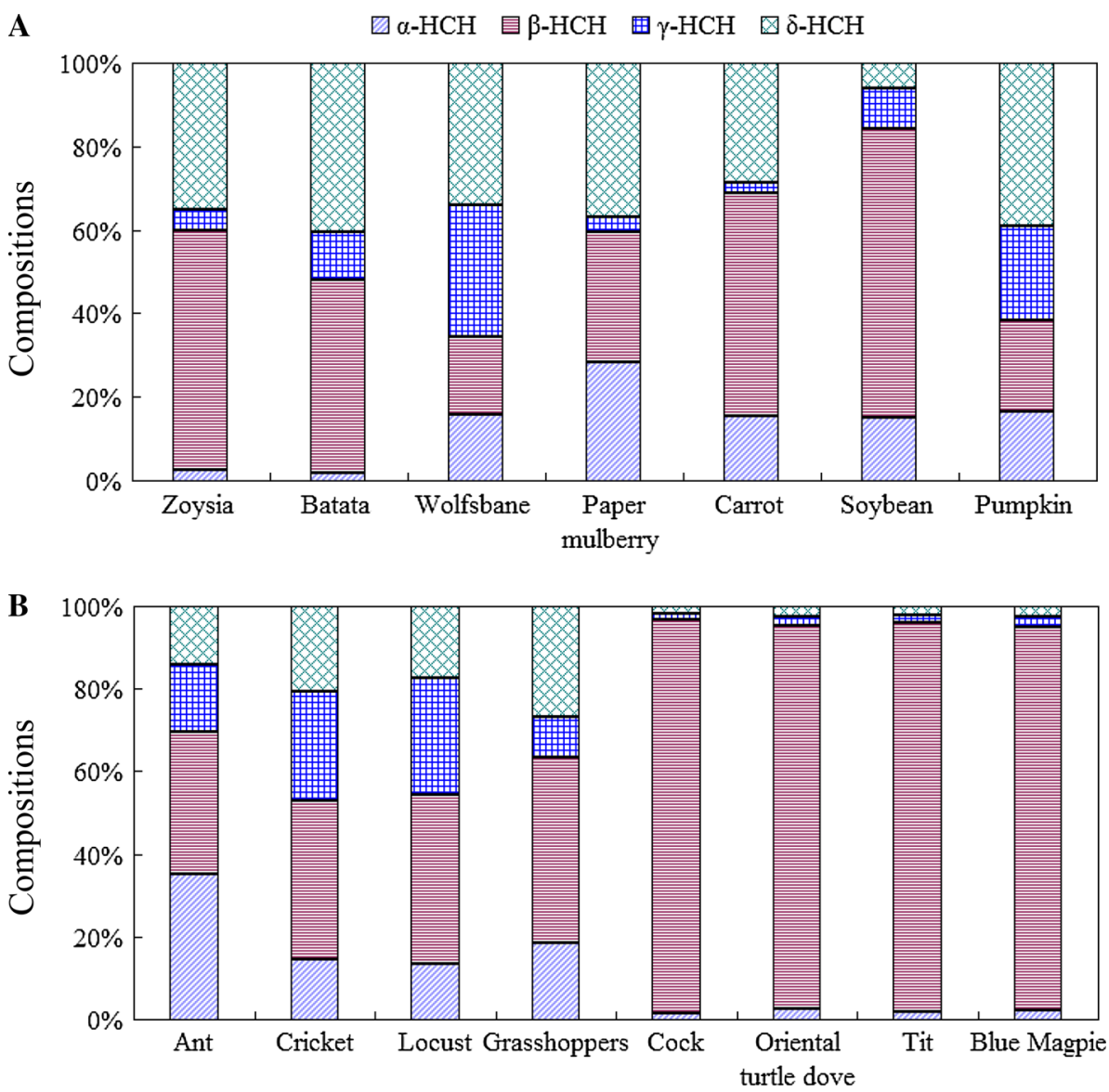

residues ranged from 9.81 to $280 \mathrm{ng} \mathrm{g}^{-1}$ lipid weight (lw) for $\Sigma \mathrm{HCHs}$, and from 9.29 to $407 \mathrm{ng} \mathrm{g}^{-1} \mathrm{lw}$ for $\Sigma$ DDTs.

OCP levels in insects differed among species: ant $>$ cricket $>$ locusts $>$ grasshoppers. The interspecies differences in OCP accumulation may be due to diet and habitat. In the four insects investigated, the proportion of $\beta$ $\mathrm{HCH}$ ranged from 38.1 to $44.6 \%$, with an average of $39.5 \%$. $\beta$-HCH was the most prevalent isomer in insects, probably due to its greater resistance to enzymatic degradation, lipophilicity, and its bioaccumulation potential (Tanabe et al. 1998). $\Sigma$ DDT concentrations in the insects ranged from 32.6 to $407 \mathrm{ng} \mathrm{g}^{-1} \mathrm{lw}$, with a mean value of $146 \mathrm{ng} \mathrm{g}^{-1} \mathrm{lw}$. To the best of our knowledge, no previous studies have investigated OCP residues in nontarget terrestrial insects in a natural environment. As shown in Fig. 2b, higher DDT accumulation in insects might be attributed to frequently elevated exposure to heavily polluted soils in this area. Among the individual DDT analogs, $p, p^{\prime}$-DDD was the predominant congener in the insects, contributing an average of $31.2 \%$ of the $\Sigma$ DDT, followed by $p, p^{\prime}$-DDT $(18.0 \%)$. The ratios of (DDD + DDE)/DDT were much higher than 1.0, and the concentrations of DDD were greater than those of DDE (Fig. 2b). The high levels of $p, p$-DDD found in our study may be linked to the anaerobic degradation of DDT and direct exposure to DDD via food chains.

The OCP residues were also measured in muscle samples from free-range chickens and wild birds. The mean residuals of HCHs and DDTs in chicken (lipid content, $0.70 \%$ ) were 85.6 and $23.1 \mathrm{ng} \mathrm{g}^{-1} \mathrm{lw}$, respectively. Tao et al. (2009) reported that the mean lipid weight concentrations of HCHs and DDTs were 6.96 and $15.8 \mathrm{ng} \mathrm{g}^{-1} \mathrm{lw}$, in chicken muscle samples collected from a poultry farm in Beijing in 2006, which are substantially lower than those observed in the present study. Levels of OCP residuals in chicken muscle measured in this study were higher than those recently reported for samples from 13 Chinese markets, where DDTs were detected in only $42.3 \%$ of total samples and HCHs were quantifiable in $<40 \%$ of the samples (Zhou et al. 2010). In the study area, OCP concentrations in the oriental turtle dove, great tits, and blue magpies were in the same order of magnitude (Fig. 2a). Data for OCP concentrations in these three birds from other areas are scarce; however, as shown in Table 3, the OCP concentrations in the birds in this study were comparable to those in omnivorous birds from other regions (Dhananjayan et al. 2011; Zhang et al. 2011). Conversely, the OCP levels in these studied birds were lower than those reported 
Fig. 4 The composition of DDTs in the plants (a) and terrestrial animals (b) from the former pesticide producing area, Southwest China
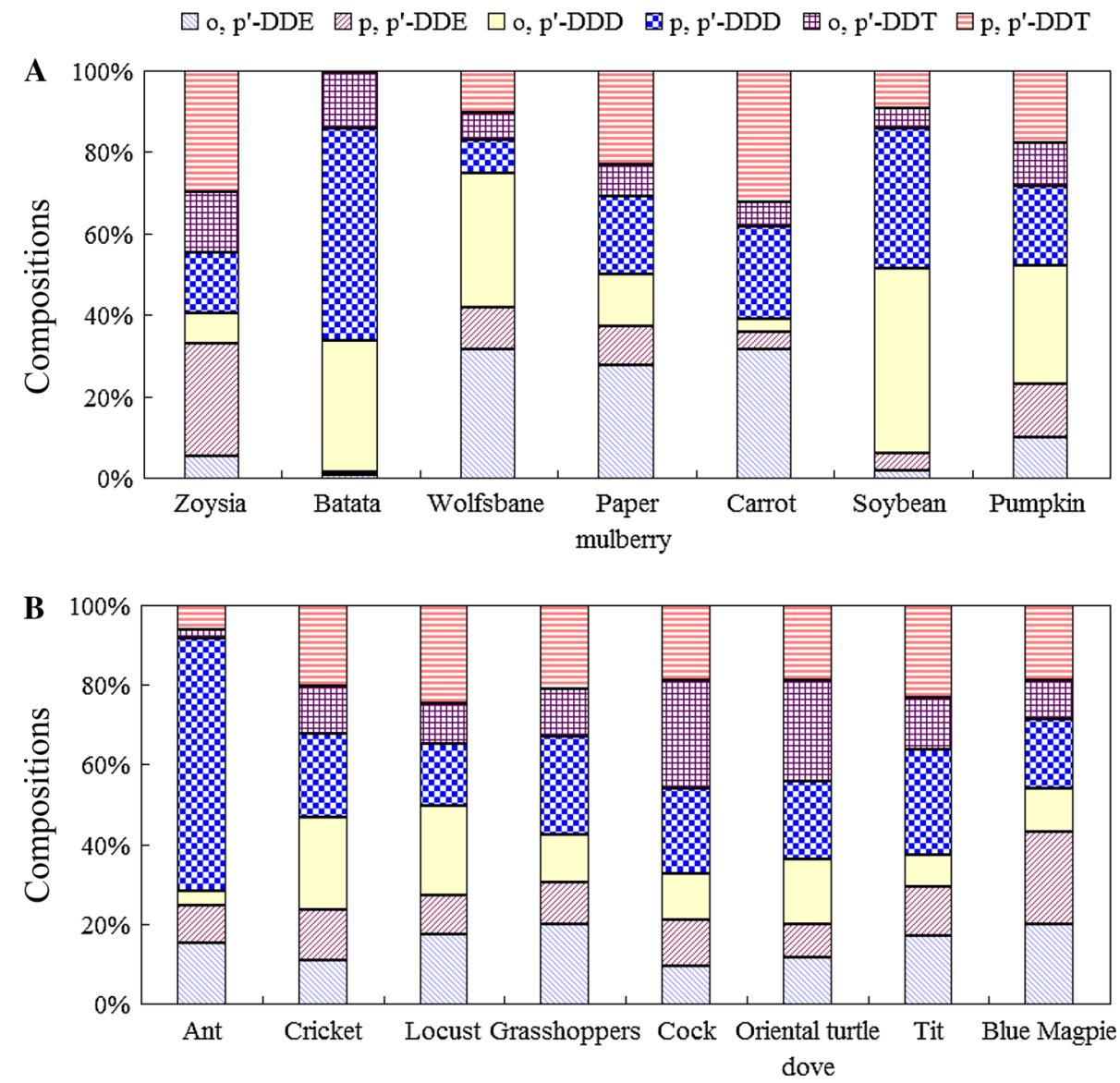

in house sparrows from Tamil Nadu, India (Dhananjayan et al. 2011). The consistent levels of contamination in birds observed in this study are understandable since the birds are all migratory species. Dietary composition and metabolic capacity of pollutants may also affect OCP accumulation in birds.

Figures $3 b$ and $4 b$ show the compositions of HCHs and DDTs measured in chickens and other birds. $\beta-\mathrm{HCH}$ was the predominant isomer in the biological samples, contributing an average of $88.3 \%$ of the $\Sigma$ HCHs. $p, p^{\prime}$-DDT dominated the DDT-related compounds. The composition profiles of both $\mathrm{HCHs}$ and DDTs of chickens and birds differed from those of plants in the area (Figs. 3, 4). Although ingestion was the dominant exposure pathway of chickens and birds to OCPs, the variations in metabolic rates of different chemicals likely resulted in the difference in composition profiles, which was demonstrated by the difference in composition profiles between feed and droppings of chickens in a previous study (Tao et al. 2009). $\mathrm{HCH}$ are largely represented by $\beta-\mathrm{HCH}$ because of the relatively higher metabolic rate of $\alpha-\mathrm{HCH}$ and greater persistence of $\beta-\mathrm{HCH}$. The ratios of (DDD $+\mathrm{DDE}) / \mathrm{DDT}$ were $>1.0$ in all samples from the chickens and wild birds, indicating that the technical DDT was further degraded in these species or their feedstuffs. The higher levels of DDD compared to DDE found in our study may be associated with anaerobic degradation of DDT or direct exposure to DDD via food chains.

\subsection{Levels and distribution of HCBD}

The HCBD concentrations ranged from $<0.02$ to $5.59 \mathrm{ng} \mathrm{g}^{-1} \mathrm{dw}$ in the soil samples (Table 1). Although the mean HCBD concentrations in soils from within the pesticide factory were higher than from the surrounding areas, this difference was not significant $(p=0.136)$. The TOC content of soil significantly affected the distribution of HCBD $(r=0.483, p<0.05)$. Surprisingly, the HCBD level in soils was not high in the study area. Tang et al. (2014) found HCBD concentrations between $<0.02$ and $3.10 \mathrm{ng} \mathrm{g}^{-1} \mathrm{dw}$ in soils from an agricultural area in East China and Zhang et al. (2014) reported that the concentrations in soil around a pesticide plant had a range of 0.04-3.33 $\mathrm{ng} \mathrm{g}^{-1} \mathrm{dw}$. The HCBD concentrations in soils in this study were much lower than those reported in soils from plants producing perchloroethylene and trichloroethylene in the United States (USEPA 1976). Compared with those areas, the surface soils within and around 
the abandoned pesticide factory have rather low levels of HCBD pollution. There are few data available regarding the persistence of HCBD in soils. Environment Canada (1999) and Taylor et al. (2003) reported that HCBD may not degrade in soil under anaerobic conditions. However, Bosma et al. (1994) found the removal of HCBD under anaerobic conditions after 4 months of acclimation, but no removal over 3 years under aerobic, non-reductive conditions. It is difficult to differentiate the historical HCBD emissions from those associated with the former factory since the levels of the main degradation product from HCBD in soils were not analyzed in this study.

As shown in Fig. 2a, the HCBD concentrations in the seven plants analyzed were $0.03-24.6 \mathrm{ng} \mathrm{g}^{-1} \mathrm{dw}$ $\left(\right.$ mean $=7.33 \mathrm{ng} \mathrm{g}^{-1}$ ). Large interspecies differences were observed in the HCBD content of the plants, with the highest concentration being found in the leaves of paper mulberry, followed by those of zoysia. Only a few studies of HCBD residues in terrestrial plants have been published to date. Grapes from the United Kingdom reportedly contained $3.7 \mathrm{ng} \mathrm{g}^{-1}$ of HCBD (McConnell et al. 1975), and Tang et al. (2014) found HCBD concentrations of $0.8-2.0 \mathrm{ng} \mathrm{g}^{-1} \mathrm{dw}$ in six plants from an agricultural area in China. In a previous study, HCBD was found to be strongly bioaccumulated by rice and vegetables, even though low HCBD concentrations were observed in the soil they grew in (Tang et al. 2014). The results of the present study further confirm the strong potential for HCBD to become concentrated in plants.

Hexachlorobutadiene concentrations of $1.65-3.80 \mathrm{ng} \mathrm{g}^{-1}$ $1 \mathrm{w}$ were found in the terrestrial animals (Fig. 2b). In contrast to the plant samples, only small interspecies differences were observed in the HCBD concentrations in the animals. Tang et al. (2014) found HCBD concentrations of $1.30-8.20 \mathrm{ng} \mathrm{g}^{-1} \mathrm{lw}$ in terrestrial animals from a farm in China, while HCBD concentrations ranging from below the detection limit to $4.90 \mathrm{ng} \mathrm{g}^{-1}$ lw were observed in terrestrial animals from Greenland (Vorkamp et al. 2004). However, higher HCBD concentrations (5.7-13.7 $\mathrm{ng} \mathrm{g}^{-1}$ wet weight) were found in human liver samples, which was likely due to hepatic metabolism of HCBD (IPCS 1994). The low HCBD concentrations in the animals investigated here might be related to the low level of HCBD pollution in soils and plants in this area. Furthermore, HCBD was found to be removed from animals within $72 \mathrm{~h}$ via urine and feces in a study employing radiolabeled HCBD (IPCS 1994). This rapid depuration rate might play an important role in the low levels of HCBD in animals.

\subsection{Potential ecological risks}

The potential risk of OCPs in soil was evaluated according to soil-quality guidelines. Soil concentrations of DDT in one third of the investigated sites, and of HCHs in almost all the sites studied exceeded the Romanian soil regulatory levels (alert level in the agricultural/residential area: $\Sigma$ DDTs, $500 \mathrm{ng} \mathrm{g}^{-1} ; \quad \alpha-\mathrm{HCH}, \quad 100 \mathrm{ng} \mathrm{g}^{-1} ; \quad \beta-\mathrm{HCH}$, $50 \mathrm{ng} \mathrm{g}^{-1} ; \gamma-\mathrm{HCH}, 20 \mathrm{ng} \mathrm{g}^{-1}$ ), respectively, implying wide soil pollution in the studied area (Ene et al. 2012). Within the former pesticide factory, one third of the sites had $\mathrm{HCH}$ and DDT levels far greater than the guideline values (industrial soils: $\Sigma \mathrm{HCHs}, 4000 \mathrm{ng} \mathrm{g}^{-1} ; \Sigma$ DDTs, $1700 \mathrm{ng} \mathrm{g}^{-1}$ ) based on China's first nationwide survey of soil pollution (MEP 2008) and the Dutch soil intervention values of DDTs (DDT, $1700 \mathrm{ng} \mathrm{g}^{-1}$; DDE, $2300 \mathrm{ng} \mathrm{g}^{-1}$ ) and $\mathrm{HCHs}\left(\beta-\mathrm{HCH}, 1600 \mathrm{ng} \mathrm{g}^{-1} ; \gamma-\mathrm{HCH}, 1200 \mathrm{ng} \mathrm{g}^{-1}\right)$ (VROM 2009). These findings indicate that there is a highlevel risk of pollution in the former OCP factory region and that on-site remediation technologies are needed to eliminate OCP contamination. OCP levels exceeding the allowed concentrations were observed in most of the soils collected from the area surrounding the abandoned factory based on China's environmental quality evaluation standard for farmland used to cultivate edible agricultural products (HJ/T 332-2006; $\Sigma \mathrm{HCHs}, 100 \mathrm{ng} \mathrm{g}^{-1}$; $\Sigma$ DDTs, $100 \mathrm{ng} \mathrm{g}^{-1}$ ). The levels of OCPs were also above the limit for contaminants in residential sites of the Canadian Environmental Quality Guidelines (CCME 2007) in some soil samples surrounding the former factory, implying that land in this area would only be suitable for residential purposes if effective soil remediation was conducted. Based on these results, we conclude that heavy soil pollution has occurred in the study area, which may have caused long-term eco-toxicological damage within and around the abandoned pesticide factory.

The OCP levels in some of the plant samples exceeded the limits set by the European Commission (2006), which specifies $\gamma$-HCH, $o, p^{\prime}$-DDE, $p, p^{\prime}$-DDE, $o, p^{\prime}$-DDD, $o, p^{\prime}$ DDT, and $p, p^{\prime}$-DDT limits of 10, 50, 50, 50, 50, and $50 \mathrm{ng} \mathrm{g}^{-1}$, respectively, for some edible leaf vegetables and feed of plant origin. In the present study, the $\mathrm{HCH}$ and DDT levels in four of the plants exceeded the maximum residue limits (MRLs) for pesticides in China's food safety standard (GB 2763-2012; leaf vegetables: $\Sigma \mathrm{HCHs}$, $50 \mathrm{ng} \mathrm{g}^{-1}$; DDDTs, $50 \mathrm{ng} \mathrm{g}^{-1}$ ). These comparisons suggest that moderate OCP pollution is present in plants in the region, indicating the potential for negative impacts on human and animal health through food chains.

The OCP levels in chickens did not exceed the maximum residue limits for pesticides in China's food safety standard ( $\Sigma \mathrm{HCHs}, 100 \mathrm{ng} \mathrm{g}^{-1}$; $\Sigma$ DDTs, $200 \mathrm{ng} \mathrm{g}^{-1}$ ), or the FAO/WHO's maximum residue limits $(\gamma-\mathrm{HCH}$, $100 \mathrm{ng} \mathrm{g}^{-1}$ fat, $\Sigma$ DDTs, $5000 \mathrm{ng} \mathrm{g}^{-1}$ fat) (FAO/WHO 2004), indicating that the consumption of chickens would not pose an immediate risk to local residents. The average concentrations of $p, p^{\prime}$-DDE of $20-1000 \mu \mathrm{g} \mathrm{g}^{-1} \mathrm{lw}$ in the 
liver of birds pose a threat to individual bird reproduction and therefore the overall population (Tanabe et al. 1998). No avian toxicity reference value is available for $\mathrm{HCHs}$, but the hatch ability of ring-necked pheasants and American kestrel eggs was not affected by concentrations of $\beta$ $\mathrm{HCH}$ and $\gamma-\mathrm{HCH}$ as high as 10 and $5.5 \mu \mathrm{g} \mathrm{g}^{-1}$ ww, respectively (Wiemeyer 1996). Owing to the much lower levels of HCHs and DDTs observed in the muscles of birds, current OCP concentrations would not likely cause adverse effects on the reproduction of avian species in the study area. However, it should be noted that OCP concentrations were not determined in the livers and eggs of birds in the present study. To the best of our knowledge, no investigations of the toxicological levels of OCPs in terrestrial nontarget insects have been conducted to date. Greater attention should be given to the possible harmful impacts of the accumulated OCPs in terrestrial insects.

The HCBD concentrations detected in all soil samples were below the guideline value $\left(1.0 \mu \mathrm{g} \mathrm{g}^{-1}\right)$ for uncontaminated soils set by the Chinese standard for soil-quality assessment for exhibition sites (SEPA 2007), as well as the concentration limits of 6.7 and $10.0 \mathrm{ng} \mathrm{g}^{-1}$ for agricultural coarse- and fine-grained soils, respectively, recommended in the environmental quality standard draft for Saskatchewan, Canada (Saskatchewan Ministry of Environment 2011). These findings indicate that only low-level HCBD pollution was present in soils from the contaminated site. The HCBD concentrations in animals analyzed in this study were lower than those reported in several previous studies (Gabrielsen et al. 2004; POPRC 2013; Tang et al. 2014), and much lower than the concentrations given in an HCBD hazard assessment for animals (POPRC 2013); accordingly, the levels in the study area are probably insufficient to cause observable adverse effects on wildlife.

\section{Conclusion}

This study clearly demonstrated that the former pesticideproducing site and its surrounding area have been seriously contaminated by OCPs. Effective soil remediation is needed within the former factory to eliminate OCP contamination from the soils. Additionally, the high concentrations of HCHs and DDTs in soils revealed that there could be eco-toxicological damage around the factory. As expected, higher levels of OCPs were found in plants from the surrounding areas of the point sources; accordingly, these compounds have the potential to induce adverse biological effects in humans and other animals. In this investigation, moderate levels of OCP pollution were also observed in terrestrial insects, free-range chickens or birds from the former pesticide-producing area. HCBD was found to be widely distributed in soils, plants, and terrestrial fauna, but
HCBD residues were generally within safe levels in the study area. Given the potential risk of these chemicals to wildlife and human health, continual monitoring and environmental and health risk assessments are needed in this region.

Acknowledgments This research was supported by the Special Fund for Public Service Sector of the State Environmental Protection Agency of China (No. 201309023), the National Natural Science Foundation of China (No. 41001329), and the Fundamental Research Funds for the Central Universities (No. 15MS60).

\section{References}

Abhilash PC, Singh N (2008) Distribution of hexachlorocyclohexane isomers in soil samples from a small scale industrial area of Lucknow, North India, associated with lindane production. Chemosphere 73:1011-1015

Aislabie JM, Richards NK, Boul HL (1997) Microbial degradation of DDT and its residues: a review. N Z J Agric Res 40:269-282

Bopp RF (1982) Chlorinated hydrocarbons and radionuclide chronologies in sediments of the Hudson River and Estuary, New York. Environ Sci Technol 16:666-676

Bosma TN, Cottaar FH, Posthumus MA, Teunis CJ, van Veldhuizen A, Schraa G, Zehnder AJ (1994) Comparison of reductive dechlorination of hexachloro-1,3-butadiene in Rhine sediment and model systems with hydroxocobalamin. Environ Sci Technol 28:1124-1128

CCME (Canadian Council of Ministers of the Environment) (2007) Canadian soil quality guideline for the protection of environmental and human health http://st-ts.ccme.ca

Dauwe T, Van den Steen E, Jaspers VLB, Maes K, Covaci A, Eens M (2009) Interspecific differences in concentrations and congener profiles of chlorinated and brominated organic pollutants in three insectivorous bird species. Environ Int 35:369-375

Dhananjayan V, Muralidharan S, Ranapratap S (2011) Organochlorine pesticide residues in eggs and tissues of House Sparrow, Passer domesticus, from Tamil Nadu, India. Bull Environ Contam Toxicol 87:684-688

Ene A, Bogdevich O, Sion A (2012) Levels and distribution of organochlorine pesticides (OCPs) and polycyclic aromatic hydrocarbons (PAHs) in topsoils from SE Romania. Sci Total Environ 439:76-86

Environment Canada (1999) Priority substances list assessment report for hexachlorobutadiene. ISBN 0-662-29297-9. Cat. no. En40$215 / 58 \mathrm{E}$

European Commission (2006) Commission amending Regulation (EC) No 396/2005 of the European Parliament and of the Council to establish Annex I listing the food and feed products to which maximum levels for pesticide residues apply. Official Journal of the European Union

FAO/WHO (Food and Agriculture Organization of the United Nations/World Health Organization) (2004) Codex alimentarius maximum residue limits. http://www.codexalimentarius.org/stan dards/pesticide-mrls

Gabrielsen GW, Knuden LB, Verreault J, Pusk K, Muir DC, Letcher RJ (2004) Halogenated organic contaminants and metabolites in blood and adipose tissue of polar bears (Ursus maritimus) from Svalbard. SFT project 6003080. Norsk Polar Institut. SPFO report 915

Gao F, Jia J, Wang X (2008) Occurrence and ordination of dichlorodiphenyltrichloroethane and hexachlorocyclohexane in 
agricultural soils from Guangzhou, China. Arch Environ Contam Toxicol 54:155-166

Guo W, Zhang H, Cui S, Xu Q, Tang Z, Gao F (2014) Assessment of the distribution and risks of organochlorine pesticides in core sediments from areas of different human activity on Lake Baiyangdian, China. Stoch Environ Res Risk Assess 28:1035-1044

IPCS (International Programme on Chemical Safety) (1994) Environmental health criteria 156, hexachlorobutadiene. World Health Organization, Geneva

Li YF, Cai DJ, Shan ZJ, Zhu ZL (2001) Gridded usage inventories of technical hexachlorocyclohexane and lindane for China with $1 / 6^{\circ}$ latitude by $1 / 4^{\circ}$ longitude resolution. Arch Environ Contam Toxicol 41:261-266

Lin Y (1996) Can usage of lindane be extended? Sci Manag Pestic 59:30 (in Chinese)

Lin J, Yang W, Zhang J, Wang A, Zhou L (2008) Residual characteristics of pesticides in representative plants in hilly and plain region in Sichuan province. Sci Agric Sin 41:4100-4108 (in Chinese)

Liu C, Li K, Yu L, Xu Y, Huang B, Wu J, Wang Z (2013) POPs and their ecological risk in sewage sludge of waste water treatment plants in Beijing, China. Stoch Environ Res Risk Assess 27:1575-1584

McConnell G, Ferguson DM, Pearson CR (1975) Chlorinated hydrocarbons and the environment. Endeavor 34:13-18

MEP (Ministry of Environmental Protection of the People's Republic of China) (2008) Notice for issuing the technical guidelines for soil environment quality assessments for National General Survey on Soil Contamination. MEP ((2008)39) (in Chinese)

Mishra K, Sharma RC, Kumar S (2012) Contamination levels and spatial distribution of organochlorine pesticides in soils from India. Ecotoxicol Environ Saf 76:215-225

Pan J, Gai N, Tang H, Chen S, Chen D, Lu G, Yang Y (2014) Organochlorine pesticides and polychlorinated biphenyls in grass, yak muscle, liver, and milk in Ruoergai high altitude prairie, the eastern edge of Qinghai-Tibet Plateau. Sci Total Environ 491-492:131-137

POPRC (Persistent Organic Pollutants Review Committee) (2013) Hexachlorobutadiene draft risk management evaluation (Second draft). http://chm.pops.int/Convention/POPsReviewCommittee/ PreviousMeetingsDocuments/POPRC8/POPRC8Followup/tabid/ 2911/Default.aspx

Qiu X, Zhu T, Yao B, Hu J, Hu S (2005) Contribution of dicofol to the current DDT pollution in China. Environ Sci Technol 39:4385-4390

Qu W, Suri RP, Bi X, Sheng G, Fu J (2010) Exposure of young mothers and newborns to organochlorine pesticides (OCPs) in Guangzhou, China. Sci Total Environ 408:3133-3138

Rojas-Squella X, Santos L, Baumann W, Landaeta D, Jaimes A, Correa JC, Sarmiento OL, Ramos-Bonilla JP (2013) Presence of organochlorine pesticides in breast milk samples from Colombian women. Chemosphere 91:733-739

Saskatchewan Ministry of Environment (2011) Saskatchewan environmental quality standards. Draft December 2011. Government of Saskatchewan, Saskatoon, p 6

SEPA (State Environment Protection Agency of China) (2007) Environmental quality evaluation standard for farmland of edible agricultural products (HJ/T 332-2006). China Environmental Science Press, Beijing (in Chinese)

Shi Y, Lu Y, Wang T, Wang G, Luo W (2009) Comparison of organochlorine pesticides occurrence, origin, and character in agricultural and industrial soils in Beijing. Arch Environ Contam Toxicol 57:447-455

Tanabe S, Senthilkumar K, Kanna K, Subramamian AN (1998) Accumulation features of polychlorinated biphenyls and organochlorine pesticides in resident and migratory birds from South India. Arch Environ Contam Toxicol 34:387-397

Tang Z, Huang Q, Yang Y, Zhu X, Fu H (2013) Organochlorine pesticides in the lower reaches of Yangtze River: occurrence, ecological risk and temporal trends. Ecotoxicol Environ Saf 87:89-97

Tang Z, Huang Q, Cheng J, Dan Qu, Yang Y, Guo W (2014) Distribution and accumulation of hexachlorobutadiene in soils and terrestrial organisms from an agricultural area, East China. Ecotoxicol Environ Saf 108:329-334

Tao S, Xu FL, Wang XJ, Liu WX, Gong ZM, Fang JY, Zhu LZ, Luo YM (2005) Organochlorine pesticides in agricultural soil and vegetables from Tianjin, China. Environ Sci Technol 39:2494-2499

Tao S, Liu W, Li Y, Yang Y, Zuo Q, Li B, Cao J (2008) Organochlorine pesticides contaminated surface soil as reemission source in the Haihe Plain, China. Environ Sci Technol 42:8395-8400

Tao S, Liu WX, Li XQ, Zhou DX, Li X, Yang YF, Yue DP, Coveney RM (2009) Organochlorine pesticide residuals in chickens and eggs at a poultry farm in Beijing, China. Environ Pollut 157:497-502

Tarcau D, Cucu-Man S, Boruvkova J, Klanova J, Covaci A (2013) Organochlorine pesticides in soil, moss and tree-bark from North-Eastern Romania. Sci Total Environ 456-457:317-324

Taylor KW, Caux PY, Moore DRJ (2003) An ecological risk assessment of hexachlorobutadiene. Hum Ecol Risk Assess 9:511-525

USEPA (United States Environmental Protection Agency) (1976) Sampling and analysis of selected toxic substances: task 1 hexachlorobutadiene, EPA 560/6-76-015. Office of Toxic Substaces, Washington, DC

Vorkamp K, Riget F, Glasius M, Pecseli M, Lebeuf M, Muir D (2004) Chlorobenzenes, chlorinated pesticides, coplanar chlorobiphenyls and other organochlorine compounds in Greenland biota. Sci Total Environ 331:157-175

VROM (Volkshuisvesting, Ruimtelijke Ordening en Milieu) (2009) Soil Remediation Circular 2009. http://rwsenvironment.eu/sub jects/soil/legislation-and/soil-remediation

Walker K, Vallero DA, Lewis RG (1999) Factors influencing the distribution of lindane and other hexachlorocyclohexanes in the environment. Environ Sci Technol 33:4373-4378

Wang XP, Yao TD, Cong ZY, Yan XL, Kang SC, Zhang Y (2007) Distribution of persistent organic pollutants in soil and grasses around Mt. Qomolangma, China. Arch Environ Contam Toxicol $52: 153-162$

Wiemeyer SN (1996) Other organochlorine pesticides in birds. In: Beyer WN, Heinz GH, Redmon-Norwood AW (eds) Environmental contaminants in wildlife: interpreting tissue concentrations, SETAC Special Publication Series. CRC Press, Boca Raton, pp 99-115

Willett KL, Ulrich EM, Hites RA (1998) Differential toxicity and environmental fates of hexachlorocyclohexane isomers. Environ Sci Technol 32:2197-2207

Yang D, Qi S, Zhang J, Wu C, Xing X (2013) Organochlorine pesticides in soil, water and sediment along the Jinjiang River mainstream to Quanzhou Bay, southeast China. Ecotoxicol Environ Saf 89:59-65

Yi Z, Yang W, Wu Y, Du Z, Bi J (2012) Residues and sources of HCHs and DDTs in tea Leaves in Fujian Tea Gardens. J AgroEnviron Sci 31:24-29 (in Chinese)

Yu SQ, Tang W, Lu B (2011) Distribution and risk assessment of $\mathrm{HCH}$ and DDT in an abandoned pesticide factory site. Chin J Envirion Sci 32:2645-2653 (in Chinese)

Zhang H, Luo Y, Li Q (2009a) Burden and depth distribution of organochlorine pesticides in the soil profiles of Yangtze River 
Delta Region, China: implication for sources and vertical transportation. Geoderma 153:69-75

Zhang L, Dong L, Shi S, Zhou L, Zhang T, Huang Y (2009b) Organochlorine pesticides contamination in surface soils from two pesticide factories in Southeast China. Chemosphere 77:628-633

Zhang X, Luo X, Liu J, Luo Y, Chen S, Mai B (2011) Polychlorinated biphenyls and organochlorinated pesticides in birds from a contaminated region in South China: association with trophic level, tissue distribution and risk assessment. Environ Sci Pollut Res 18:556-565

Zhang H, Wang Y, Sun C, Yu M, Gao Y, Wang T, Liu J, Jiang G (2014) Levels and distributions of hexachlorobutadiene and three chlorobenzenes in biosolids from wastewater treatment plants and in soils within and surrounding a pesticide plant in China. Environ Sci Technol 48:1525-1531

Zhao C, Xie H, Zhang J, Xu J, Liang S (2013) Spatial distribution of organochlorine pesticides (OCPs) and effect of soil characters: a case study of a pesticide producing factory. Chemosphere 90:2381-2387

Zhou P, Chen H, Zhao Y, Wu Y, Yan S (2010) Analysis on persistent organochlorine pesticide multiresidues in animal origin foods. Chin J Food Hygi 22:193-198 (in Chinese)

Zhu YF, Liu H, Xi ZQ, Cheng HX, Xu XB (2005) Organochlorine pesticides (DDTs and $\mathrm{HCHs}$ ) in soils from the outskirts of Beijing, China. Chemosphere 60:770-778 